\title{
Reflexões periféricas sobre a difusão internacional do pensamento econômico
}

José Luis Cardoso

Instituto de Ciências Sociais, Universidade de Lisboa

\begin{abstract}
Palauras-chave
pensamento econômico, história nacional, difusão internacional, Cepal.
\end{abstract}

Classificação JEL B00

Key words

economic thought; national history; international diffusion; CEPAL.

JEL Classification $B 00$

\section{Resumo}

Este artigo discute o tema da difusão internacional das ideias e teorias econômicas, explicando a sua relevância para a compreensão do processo de formação do pensamento econômico à escala nacional. Explora diversos exemplos elucidativos do fluxo internacional da ciência econômica e procede a um balanço das principais perspectivas historiográficas construídas sobre o tema. Recorre ao exemplo da influência que as doutrinas e teorias da Comissão Econômica para a América Latina e o Caribe (Cepal) - especialmente aos desenvolvimentos dados por Raul Prebisch e Celso Furtado - tiveram em Portugal e Espanha, durante a década de 1950, ilustrando um caso atípico de influência da periferia sobre países semiperiféricos. $\mathrm{O}$ argumento principal apresentado neste artigo consiste em afirmar a importância do estudo da difusão internacional do pensamento econômico, quer melhor compreensão do processo de formação da ciência econômica, quer uma tomada de consciência das suas implicações sobre o funcionamento e a mudança da realidade econômica e social num contexto nacional determinado.

\section{Abstract}

This article discusses the broad topic of the international diffusion of economic ideas and theories, by stressing its relevance for a better understanding of the process of formation of economic thought on a national scale. The article explores several meaningful examples of the international flow of economics and presents a brief survey of the main historiographical approaches available. It gives special emphasis to the influence of CEPAL (ECLA, United Nations Economic Commission for Latin America) - namely through the writings of Raul Prebisch and Celso Furtado - in Portugal and Spain in the 1950s, which features an atypical case of a peripheral influence on semi-peripheral countries. The article's main claim is that the study of international diffusion of economic thought sheds new light onto both the very understanding of the building of economics as a science and the awareness of its implications on the functioning and change of economic reality within a given national context. 


\section{1_Introdução}

Nos estudos sobre história do pensamento econômico, é frequente a interrogação acerca da pertinência e da legitimidade em se reclamar a paternidade e a nacionalidade de doutrinas e teorias que, uma vez expostas e bem sustentadas, se acomodam e utilizam em ambientes diversos que lhes conferem caráter universal. Assim, será certamente descabido e absurdo dizer que a teoria econômica neoclássica ou keynesiana possui uma pátria, o mesmo se aplicando a qualquer outro legado da ciência econômica construída ao longo do tempo e beneficiando de contribuições provenientes de diferentes contextos históricos e geográficos.

Todavia, essa recusa em conferir uma espécie de selo de origem aos contributos científicos, cujo alcance se pretende universal, não significa idêntica recusa em admitir a especificidade própria dos problemas que suscitam a inquietação intelectual de economistas e decisores políticos que, em épocas distintas e em espaços nacionais próprios, reclamam da ciência econômica uma função de interpretação da realidade e de auxílio nos processos de decisão que implicam o desenho e a aplicação de medidas de política econômica. Por conseguinte, a ciência econômica não é - ou, mais prudentemente, não deve nem pode ser-indiferente aos problemas concretos que procura explicar e resolver. E é justamente por tal motivo que se afigura fundamental discutir, no plano metodológico, os problemas associados à difusão de ideias econômicas que, na sua busca de universalidade, rasgam horizontes e fronteiras e surgem reclamadas ou aplicadas em distintos territórios e instâncias de conhecimento e poder.

Esse enunciado geral serve para introduzir a motivação primordial deste texto, que procura demonstrar a importância da análise do fluxo internacional de ideias econômicas, tomando como exemplo central a influência da escola estruturalista de desenvolvimento econômico da Comissão Econômica para a América Latina e o Caribe (Cepal) em países da semiperiferia do sistema capitalista, nomeadamente em Portugal e na Espanha. Através da atenção dada a esse caso (seção 4), espero que seja possível ilustrar o impacto que a circulação de ideias opera sobre a definição e execução de políticas e reformas econômicas. Antes de fazê-lo, porém, e uma vez que o argumento aqui defendido é justamente o de considerar que os fluxos de ideias enriquecem a formação do pensamento econômico à escala nacional, começarei por destacar o significado da elaboração de histórias nacionais de pensamento econômico (secção 2). Tais histórias não impedem 
nem rejeitam uma visão cosmopolita sobre a circulação de ideias, conforme tem vindo a ser devidamente assinalado pela herança historiográfica corrente e pelos diversos exemplos de estudos de caso de que se faz breve balanço (seção 3), e dos quais se extraem alguns ensinamentos (seção 5).

\section{2_O lugar das histórias nacionais do pensamento econômico}

A relevância deste tema decorre, em primeiro lugar, da vasta amplitude dos assuntos associados à expressão pensamento econômico. Com efeito, aqui se acomodam matérias que dizem respeito quer aos quadros ideológicos, doutrinais e normativos em que se movem os que cultivam a ciência econômica, quer aos métodos, conceitos e técnicas de análise a que recorrem, quer ainda às implicações das suas teorias na definição de orientações de política econômica. Ou seja, os objetos em estudo revelam que a economia, conquanto campo de pesquisa científica, não é imune a pressupostos baseados em juízos de valor, nem é alheia às aplicações e usos a que inevitavelmente se sujeita. Esses são motivos de sobra para que o processo de transmissão internacional do pensamento econômico - seja no centro, seja na peri- feria, seja ainda na semiperiferia do capitalismo - adquira uma pertinência acrescida, na medida em que permite aprofundar a relação íntima que a formação e a difusão da ciência econômica mantêm com os ambientes e contextos sociais que suscitam o seu uso e apropriação.

Um importante esforço de sistematização dessas matérias foi levado a cabo por Lluch (1980) num texto que, por ser escrito em castelhano, acabou por se tornar vítima de um dos problemas que discutem a propósito dos obstáculos à transmissão do pensamento econômico inovador, isto é, o desconhecimento provocado por barreiras de linguagem.

A principal novidade trazida por Lluch (1980) - o qual viria a ser mais tarde retomado e ampliado em Lluch (1999) consiste na articulação que estabelece entre a análise da transmissão internacional e a definição das especificidades de uma história nacional do pensamento econômico. Nesse tipo de abordagem, mantém-se o pressuposto de que os fenômenos de intercâmbio cultural em nível internacional são uma característica natural da experiência diária, quer na vida acadêmica, quer na vida profissional. Todavia, a facilidade de tal processo de intercâmbio pode estar sujeita a constrangimentos ou restrições de diverso tipo. A situação econômica e política vi- 
vida nos países periféricos ajuda a compreender melhor o alcance de tais restrições.

Um primeiro tipo de restrição prende-se com o desenvolvimento dos meios de transmissão, designadamente a velocidade de circulação de livros estrangeiros, a facilidade de acesso a revistas de topo, o conhecimento geral de outras línguas, a quantidade e a qualidade das traduções e as condições para o estabelecimento de contatos internacionais, tanto em nível individual quanto em nível institucional. Está também dependente do grau de autonomia científica ou de reconhecimento acadêmico que, em determinadas circunstâncias históricas, a ciência econômica possa ter atingido em determinado país ou área geográfica. Esse tipo está ainda relacionado com as diferenças de nível de desenvolvimento econômico entre o país de origem e o país receptor, diferenças essas que podem ser mais ou menos visíveis conforme o período histórico considerado.

Um segundo grande tipo de restrição reside, essencialmente, na existência de relações duradouras de desequilíbrio entre países que têm longa tradição de inovação e criação de ciência econômica e países aos quais apenas resta a opção de adaptar e usar o discurso científico criado no estrangeiro. Poderemos ser tentados a pensar que, nos países que nunca estiveram na vanguarda de desenvolvimentos teóricos, a história do pensamento econômico se reduz a mera sucessão de influências externas. Mas, mesmo que aceitemos a ideia de que o conhecimento e a familiarização com o que é feito lá fora são um saudável sinal de cosmopolitismo, daqui não decorre que o país receptor tenha de aceitar grande parte dessas ideias, princípios analíticos e receitas práticas que apenas fazem sentido noutros ambientes históricos. Quer isso dizer que a facilidade ou dificuldade de aceitação de doutrinas, teorias e políticas econômicas está sempre condicionada pelas particularidades da realidade econômica, das instituições políticas e sociais e do ambiente científico prevalecente no país receptor. Ora, é precisamente o modo como um país utiliza e adapta as influências recebidas que torna pertinente e válido o estudo da história do pensamento econômico numa perspectiva nacional. ${ }^{1}$

\section{3_ Difusão internacional do pensamento econômico: balanço historiográfico e estudo de casos}

Não obstante a pertinência e validade das histórias nacionais de pensamento econômico, particularmente quando realizadas em países considerados periféricos, vivemos hoje num período que parece

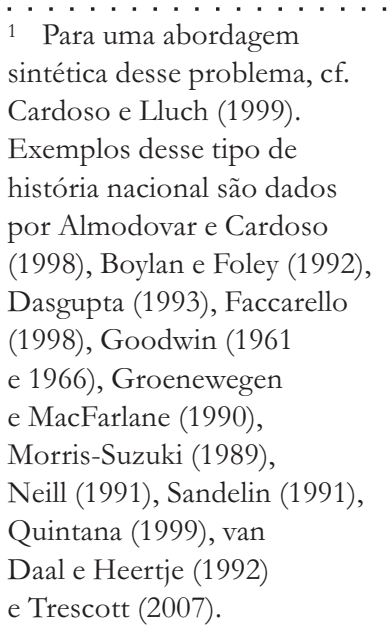

sintética desse problema, cf.

Cardoso e Lluch (1999). por Almodovar e Cardoso (1998), Boylan e Foley (1992), Dasgupta (1993), Faccarello (1998), Goodwin (1961 e 1966), Groenewegen e MacFarlane (1990), Morris-Suzuki (1989), Neill (1991), Sandelin (1991), Daal e Heertje (1992) e Trescott (2007) 
pouco propício a valorizar os méritos desse tipo de abordagem. Com efeito, são as próprias condições e formas de produção e circulação de conhecimento econômico que implicam a inevitabilidade de processos de criação e partilha em que as barreiras geográficas e linguísticas têm vindo a ser progressivamente eliminadas. Os níveis estandardizados de formalização conceptual e a aceitação quase unânime de semelhantes técnicas e instrumentos de análise têm contribuído, decisivamente, para a formação de linguagens universais com elevado potencial de comunicação internacional. Acima de tudo, dever-se-á assinalar a facilidade de transmitir e disseminar novas pistas e hipóteses de investigação, novos resultados e experiências, através de suportes usuais (revistas em papel) ou inovadores (revistas eletrônicas) que a comunidade acadêmica reconhece e credencia como veículos privilegiados de circulação do conhecimento econômico.

A constatação de que a transmissão internacional do pensamento econômico é um fenômeno normal e recorrente nada tem de original. Há mais de meio século um lúcido diagnóstico foi apresentado por Hutchison (1955).

With the vastly increased number of translations and of widely circulating specialist journals, including international journals, and with the increasingly mathematical character of advanced economic analysis, it seems, on the whole, very unlikely that good new ideas, whenever or wherever they do arise, will not have a reasonably fair chance of being heard and of making their way $[\ldots]$. Economists are now part, even often from their undergraduate years, of large, organised, internationally-linked academic machines, with their subjects closely organised and defined and their questions and categories ready formulated (Hutchison, 1955, p. 14-15).

Se pensarmos naquilo que foi, nas últimas décadas do século XX e início do século XXI, o crescimento avassalador dos instrumentos de comunicação ao alcance da comunidade acadêmica, as palavras de Hutchison adquirem um sentido autoevidente.

A sua análise teve como pretexto a gênese e a difusão dos princípios teóricos da chamada "revolução marginalista" e da economia neoclássica, sobretudo na sua componente marshalliana. Outro estudo de caso foi também realizado na mesma época por Dorfman (1955). O objeto em análise é a difusão dos princípios doutrinais da Escola Histórica Alemã nos Estados Unidos, colocando ênfase na explicação das adaptações de que foram alvo algumas das ideias importadas, de modo a tornarem-se mais consentâneas e melhor adap- 
tadas aos problemas da realidade econômica americana.

Independentemente do valor acrescentado que esses textos trazem, em termos de aprofundamento de novos objetos de pesquisa, eles valem também pelo enquadramento metodológico mínimo que procuram fixar para o estudo do fenômeno da difusão de ideias econômicas. Designadamente, ao anunciarem algumas preocupações heurísticas sobre a formação, mudança e sucessão das ideias econômicas e sobre as condições favoráveis, fatores de aceleração e obstáculos que dificultam os respectivos processos de transmissão e difusão. Outros aspectos implicitamente contidos nas reflexões pioneiras desses autores - e que viriam a ser redescobertos por Ernest Lluch nos textos a que inicialmente fiz referência (Lluch, 1980 e 1999) - são os que se referem à abordagem de condicionalismos ditados por diferentes níveis de desenvolvimento econômico e pelo maior ou menor grau de cosmopolitismo cultural e políti$\mathrm{co}$, os quais, inevitavelmente presentes em qualquer sociedade que seja tomada como referência de análise, determinam a oportunidade e a profundidade dos processos de difusão.

Dois outros autores que aprofundaram as orientações metodológicas atrás esboçadas merecem ser assinalados. Um deles é Joseph Spengler, pela apresentação que faz de um embrionário modelo de teoria da informação, no qual discute os problemas específicos com que, no caso da transmissão de ideias econômicas, se confrontam o emissor, o receptor, o meio de transmissão e o conteúdo transmitido (Spengler, 1970). O segundo autor a considerar é Craufurd Goodwin, pela tentativa de chegar a uma explicação geral sobre a relação entre a difusão das ideias e a organização social e política prevalecente, no sentido de elucidar como os diferentes agentes (economistas profissionais, decisores políticos e econômicos, jornalistas e fazedores de opinião não especializados) recorrem a ideias econômicas estabelecidas e consagradas, tendo em vista o desenvolvimento da ação social (Goodwin, 1972 e 1973).

Continuando esta abreviada incursão pela historiografia, cabe agora assinalar outra referência obrigatória para o enquadramento geral do estudo dos processos de difusão de ideias econômicas. Refiro-me ao livro editado por Colander e Coats (1989), em cuja introdução os autores enunciam as grandes questões suscitadas pela criação de modelos gerais explicativos do fenômeno em apreço. A sua abordagem desenvolve-se em torno de três modelos fundamentais: o modelo do contágio, de acordo com o qual a difusão de uma ideia pode ser 
equiparada ao alastrar de uma doença; o modelo da teoria de informação, já referido a propósito de J. Spengler; e o modelo do mercado das ideias. Relativamente a este último, merece destaque o modo como implicitamente aderem à perspectiva avançada por Stigler (1983) acerca da interpretação das razões que justificam que, em determinado período, as ideias econômicas sejam aceitas, ignoradas, recicladas ou rejeitadas. Isto é, um modelo que sujeita o processo de transmissão e apropriação a uma abordagem idêntica à que é utilizada para o estudo de qualquer outro tipo de mercado. Os textos reunidos por Colander e Coats, no entanto, conferem muito pouco destaque ao problema da difusão internacional. As temáticas privilegiadas são os processos de comunicação e difusão entre os economistas profissionais, e entre estes e o grande público e ainda entre os decisores políticos.

O modelo da teoria da informação foi, entretanto, ampliado e melhorado por Mäki (1996), mediante um enquadramento historiográfico que explica a variedade de aspectos relacionados com os processos de transmissão, seleção e adaptação de ideias econômicas e respectivo condicionamento ditado por diferentes tipos de fator interno e externo. Quanto às orientações metodológicas inspiradas na obra de Stigler (o modelo do mercado das ideias), viriam a ser aprofundadas e coerentemente aplicadas por Llombart (1995) num estudo que dedicou à recepção crítica do pensamento fisiocrático na Espanha.

A fisiocracia foi precisamente uma das escolas de pensamento econômico que até agora mereceu um tratamento mais circunstanciado na perspectiva dos estudos de processos de difusão internacional (Delmas, Demals e Steiner, 1995). Também Adam Smith tem sido objeto de estudo nesse âmbito, desde os trabalhos pioneiros sobre a difusão em países europeus do autor da Riqueza das nações (Hasek, 1925; Palyi, 1928) até as contribuições mais recentes que procuram sistematizar os motivos e as peculiaridades dos processos de difusão e recepção, a qualidade das traduções ou o impacto exercido junto dos decisores políticos (Sugiyama e Mizuta, 1988; Lai, 2000; Tribe e Mizuta, 2002). Idêntico propósito está patente na coleção de artigos publicados no número especial da revista Économies et Sociétés, Série Oeconomia, PE n. 34, 2004, dedicada ao tema da economia política neossmithiana e seu impacto em quatro países do continente europeu (França, Itália, Espanha e Portugal).

À propósito de Smith, refira-se que a sua difusão no império luso-brasileiro revestiu características bem significativas, dado que a utilização da sua obra por autores 
nascidos em território brasileiro foi bastante mais relevante e consistente do que a que ocorreu na metrópole europeia. O papel de José da Silva Lisboa como sistematizador dos princípios essenciais sustentados por Adam Smith (Lisboa, 1804) e o contributo dado pelo seu filho Bento da Silva Lisboa com a tradução em língua portuguesa da Riqueza das nações, publicada no Rio de Janeiro, em 1810-1811, foram decisivos para o apetrechamento intelectual da elite política brasileira, que aplaudiu a abertura dos portos, o fim do regime exclusivo colonial e as medidas de liberalização econômica que acompanharam a instalação da corte portuguesa no Rio de Janeiro, a partir de 1808. Nesse contexto que antecede a independência política do Brasil, as ideias de Adam Smith foram diversas vezes usadas como argumento de autoridade que servia para explicar e legitimar as mudanças em curso. Esse caso é bem elucidativo de como a difusão das ideias econômicas pressupõe a existência de condições propícias que tornam recomendável ou vantajoso o processo de apropriação e adaptação de tais ideias.

Entre outros exemplos significativos que poderiam ser relembrados, ${ }^{2}$ refira-se ainda o livro que reúne um conjunto de contribuições dedicadas à análise das influências dos economistas franceses do século XIX noutros horizontes geográficos
(Dockès et al., 2000), ou o livro que trata da penetração e impacto das ideias keynesianas na Europa, nos Estados Unidos e no Japão (Hall, 1989). Neste último caso, a questão central em análise é o confronto de experiências de decisão política e de condução da política econômica nas principais economias do mundo capitalista, entre os finais da década de 1930 e os finais da década de 1960, com os suportes teóricos e doutrinais proporcionados pela obra de John Maynard Keynes.

Os processos de internacionalização e de desenvolvimento da ciência econômica no período post-1945 constituem o objeto central de atenção de duas coletâneas de ensaios editadas por Coats (1997 e 2000). Trata-se de um esforço sequencial e integrado que demonstra as enormes potencialidades dos estudos de comparação internacional dos processos de disseminação e assimilação de ideias, teorias e políticas econômicas.

Qual a característica comum que confere a esses diferentes projetos editoriais alguma uniformização temática? Sem dúvida que é a preocupação central em fixar padrões de análise comparativa que permitem estabelecer paralelismos e complementaridades no desenvolvimento de algumas correntes de pensamento econômico em diferentes países. ${ }^{3}$ Tais casos têm merecido atenção

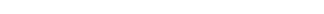

2 Para um desenvolvimento desses exemplos, cf. Cardoso (2003).

3 Sobre a importância dos estudos comparados na análise dos processos de assimilação e formação do pensamento econômico nacional, cf. Albertone e Masoero (1994). 


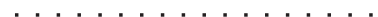

4 Por serem bem conhecidos, dispensam tratamento pormenorizado os traços essenciais do pensamento desenvolvimentista da Cepal, designadamente na sua expressão brasileira através da obra e ação de Celso Furtado. Para uma análise circunstanciada, é sempre útil a leitura de Bielschowsky (2000). suficiente e constituem exemplificação habitual na abordagem do problema da circulação e difusão das ideias econômicas à escala internacional.

\section{4_ Difusão internacional na periferia: um caso exemplar}

Gostaria agora de exemplificar com um diferente testemunho que creio servir de forma muito pertinente ao propósito de demonstrar a relevância desse processo de formação e de difusão do pensamento econômico em ambiente internacional. Com a característica muito especial de se tratar de um caso em que o sentido geográfico da influência é inverso do que habitualmente se verifica. Trata-se do caso da influência que a escola estruturalista de desenvolvimento econômico da Comissão Econômica para a América Latina e o Caribe (Cepal), criada no âmbito da Organização das Nações Unidas, no final da década de 1940, exerceu sobre a formação do pensamento econômico em Portugal e na Espanha, especialmente no que se refere à análise dos estrangulamentos ao crescimento econômico durante o período das ditaduras de Salazar e Franco.

São bem conhecidas as teses da doutrina estruturalista do desenvolvimento, que teve expressão privilegiada na obra de Raul
Prebisch, na Argentina, e de Celso Furtado, no Brasil. A intuição básica desses autores foi a constatação de uma relação desigual e assimétrica entre o centro industrializado e a periferia fornecedora de matérias-primas, relação esta em tudo idêntica à forma típica de relacionamento das velhas metrópoles imperiais com as suas colônias (cf. Prebisch, 1949). Segundo essa análise, a propagação do progresso técnico do centro para a periferia processava-se a ritmo excessivamente lento e, para se quebrar a relação de desigualdade prevalecente, era indispensável proceder à industrialização dos países periféricos através da substituição de importações de produtos que pudessem ser fabricados internamente sem agravamento das relações de dependência tecnológica. Nesse processo, caberia ao Estado um papel essencial na criação de um ambiente de proteção que fizesse uso dos habituais instrumentos de política econômica (indústria nascente e tarifas protecionistas) favoráveis ao arranque e à consolidação do setor industrial. A escola estruturalista latino-americana não inventou tais instrumentos, mas enquadrou a oportunidade de se fazer uso deles com vista a uma atenuação das desigualdades de níveis e ritmos de desenvolvimento entre países do centro e da periferia. ${ }^{4}$

Contrariando os princípios da teoria ricardiana das vantagens comparativas e 
da teoria neoclássica do comércio internacional, Prebisch, Furtado e seus seguidores demonstraram, de forma convincente, que a constante e progressiva deterioração dos termos de troca nos países periféricos não permitia manter a ilusão de que todos os países podem simultaneamente beneficiarse da expansão do comércio à escala internacional. Independentemente da comprovação empírica e do realismo conceptual dessa visão, o peso da sua componente doutrinal criou condições favoráveis à aceitação de orientações de política econômica que pudessem diminuir as diferenças entre o centro e a periferia.

O impacto das teses da escola estruturalista latino-americana ultrapassou a sua área geográfica natural. Com efeito, diversas economias situadas em outras partes do mundo, designadamente no lado norte da bacia mediterrânica, também enfrentaram problemas de atraso econômico e sentiram a necessidade de definir políticas tendentes a vencer esse atraso, pelo que se mostraram atentas aos contributos veiculados por Prebisch, Furtado e por outros economistas fiéis ao ideário da Cepal.

Condições particulares dessas sociedades, designadamente a sua natureza semiperiférica, a existência de regimes ditatoriais duradouros e a relação preferencial com os centros produtores de ideias eco- nômicas situados no continente europeu, conferiram caráter peculiar à visão estruturalista então importada.

Os efeitos fundamentais desse processo de importação de ideias foram já aflorados em relação a alguns casos nacionais, designadamente o caso espanhol (Velarde Fuertes, 1981), português (Bastien e Cardoso, 2003) e, ainda que marginalmente, ao caso grego (Psalidopoulos, 1996); foram-no também numa perspectiva comparativa envolvendo Espanha e Portugal (Love, 2004).

Estamos diante de uma situação de pesquisa que configura um caso atípico do processo de difusão internacional das ideias econômicas. Habitualmente, a direção do fluxo vai do centro para a periferia, considerando-se essa periferia na dupla vertente do seu grau de desenvolvimento econômico e do seu nível de maturidade científica e intelectual. No caso dos países ibéricos - e especificamente no que se refere à segunda metade do século XX -, é inquestionável o seu estatuto de país duplamente periférico, constituindo um caso clássico dos processos de captação, assimilação e adaptação de pensamento econômico produzido nos principais centros difusores da Europa e dos Estados Unidos.

$\mathrm{O}$ relevo que a escola estruturalista da teoria do desenvolvimento econômico 
colheu na Espanha e em Portugal remete-nos, por conseguinte, para uma situação em que o centro é representado por países ou regiões aos quais está usualmente reservada a classificação de periféricos. Nada existe de paradoxal nessa ocorrência, se tomarmos em consideração alguns elementos de proximidade entre a estrutura das economias ibéricas e a das economias subdesenvolvidas da América Latina, no período que antecede e que imediatamente sucede à $2^{\mathrm{a}}$ Guerra Mundial.

Esse cenário histórico era particularmente propício ao surgimento de preocupações desenvolvimentistas que insistiam na importância da política de protecionismo e condicionamento industrial como instrumento de convergência dos países ibéricos para os níveis de crescimento dos principais parceiros europeus. Durante as décadas de 1930 e 1940, essas ideias foram, sobretudo, protagonizadas pelo grupo profissional dos engenheiros, com interesses bem representados em algumas instâncias de decisão política relacionadas com o abastecimento energético, a modernização de vias de comunicação e o enquadramento da atividade industrial. Ainda que, na sua fundamentação, esse discurso apelasse mais ao pragmatismo e ao senso comum do que a argumentos extraídos de boa teoria econômica, não deixava de suscitar melhor co- nhecimento das condições propriamente econômicas do subdesenvolvimento ibérico e das vias para a sua superação. Deste modo, a ânsia produtivista, industrialista e tecnocrática criou um ambiente favorável à adoção de algumas das ideias e técnicas de análise características da corrente estruturalista latino-americana.

Essa aproximação estava longe de ser integral e plenamente assumida, dada a diversidade de pressupostos ideológicos em presença. Em todo o caso, era patente uma comum consciência das condições do subdesenvolvimento, existia uma postura igualmente comum de desconfiança na capacidade autorreguladora das forças espontâneas do mercado e havia em ambos os lados uma atitude favorável ao intervencionismo do Estado na regulação da ordem econômica.

\section{Balanço e ensinamentos}

Os exemplos aflorados nas seções anteriores permitem esboçar alguns ensinamentos e conclusões. Um primeiro aspecto a destacar é o reforço da convicção de que a análise dos processos de transmissão internacional ultrapassa em larga escala o âmbito limitado das abordagens convencionais da história da ciência econômica, especialmente a perspectiva cen- 
trada na reconstrução racional do conteúdo interno das suas componentes teóricas e analíticas. Com efeito, as preocupações com as questões da transmissão, assimilação e adaptação do pensamento econômico não implicam apenas um rasgar de fronteiras entre espaços econômicos distintos que comunicam e interagem de forma cada vez mais franca e globalizada. Pressupõem também a eliminação de barreiras entre territórios disciplinares que é indispensável percorrer para uma adequada compreensão dos contextos históricos, institucionais, políticos e culturais que enquadram a circulação de ideias econômicas à escala internacional.

Quando parece que tudo já foi dito sobre o significado do mais recôndito capítulo de um livro menos importante de um autor medianamente famoso, talvez valha a pena alargar a pesquisa para horizontes menos confinados. Assim, discutir o modo como as obras de, por exemplo, Adam Smith, Karl Marx, John M. Keynes ou Milton Friedman foram e são lidas, traduzidas e apropriadas em diferentes países e em contextos históricos distintos, não é matéria que diga apenas respeito a uma história local ou nacional dos processos de assimilação de doutrinas, teorias e políticas econômicas. Antes de tudo, é matéria que permite prolongar e enriquecer o conhecimento dispo- nível sobre os próprios autores que são objeto de apropriação. Quer isso dizer que a leitura seletiva e parcial da obra de um autor consagrado, o recurso que a ele se faz como símbolo de autoridade que cauciona a validade de determinados fundamentos teóricos ou receitas práticas, também constitui um acréscimo no conhecimento disponível sobre esse mesmo autor. Os grandes mestres, os wordly philosophers, não podem ser apenas avaliados por aquilo que realmente disseram, mas também pelo uso por vezes abusivo - que realmente foi feito da sua obra, internacionalmente transmitida e divulgada.

Outro atributo inerente ao estudo dos processos de transmissão é o que se refere à revisão dos pontos de vista acerca do papel efetivamente representado por antecipadores e precursores, supostamente esquecidos ou ignorados. Não é fácil lidar com a ideia de que certas teorias, habitualmente identificadas com a genialidade de uma descoberta científica perfeitamente localizada na obra de determinado autor ou grupo de autores, possam ter conhecido um diferente e anterior processo de gestação. Uma abordagem que privilegie o estudo dos processos de transmissão poderá elucidar as circunstâncias que fazem com que existam ambientes propícios à ocorrência de descobertas múltiplas e simultâneas, as 
quais obrigam a atenuar e a relativizar o relevo atribuído a agentes até então vistos como únicos e inquestionáveis inovadores.

Merece também destaque o fato de os estudos sobre o fluxo internacional das ideias econômicas, sobretudo na perspectiva do país receptor, possibilitarem uma diferente atitude em relação ao reconhecimento da importância e do impacto de correntes ou escolas heterodoxas. Os processos de transmissão internacional proporcionaram ainda a formação de uma visão crítica sobre as tentativas de criar esquemas demasiado rígidos de periodização e de arrumação de autores em escolas ou correntes de pensamento, dada a presença simultânea de distintas perspectivas e influências e dadas as especificidades da construção de um discurso econômico feito de múltiplos e contraditórios ingredientes. $\mathrm{O}$ caso aqui destacado da influência da escola da Cepal nos países ibéricos constitui uma demonstração inequívoca dessa riqueza de processos de assimilação cultural que desfazem preconceitos infundados sobre a adequação entre modelos e a realidade.

Para concluir, refira-se que todos esses aspectos relativos ao estudo dos processos de transmissão internacional podem e devem ser entendidos numa perspectiva de valorização das histórias e tradições nacionais de pensamento econômico. A in- trodução de uma dimensão nacional não pretende negar o caráter universal da ciência econômica, mas sim demonstrar a relevância de processos de assimilação e adaptação inerentes à circulação de teorias e ideias econômicas. Nesses termos, a difusão internacional do pensamento econômico constitui um poderoso instrumento que visa tanto melhor compreensão do processo de formação da ciência econômica quanto uma tomada de consciência das suas implicações sobre o funcionamento e a mudança da realidade econômica e social num contexto nacional determinado. 


\section{Referências bibliográficas}

ALMODOVAR, António; CARDOSO, José Luís. A bistory of

Portuguese Economic Thought.

London and New York:

Routledge, 1998

ALBERTONE, Manuela; MASOERO, Alberto. Political economy and national realities. Torino: Fondazione Luigi Einaudi, 1994.

BASTIEN, Carlos; CARDOSO, José Luís. Structuralism and development economics in the European semi-periphery: the case of Portugal. Notas Económicas, n. 17 , p. $36-51,2003$.

BIELSCHOWSKY, Ricardo. Pensamento econômico brasileiro. $\mathrm{O}$ ciclo ideológico do desenvolvimento. 4. ed. Rio de Janeiro: Contraponto, 2000.

BOYLAN, Thomas A.; FOLEY, Timothy P. Political economy and colonial Ireland. The propagation and ideological function of economic discourse in the nineteenth century. London and New York: Routledge, 1992.

CARDOSO, José Luís; LLUCH, Ernest. Las teorías económicas contempladas a través de una óptica nacional. In: QUINTANA Enrique Fuentes (Ed.). Economiay Economistas Españoles. Barcelona: Galaxia Gutemberg, 1999. v. 1, p. $477-484$.
CARDOSO, José Luís. The international diffusion of economic thought. In: SAMUELS, Warren; BIDDLE, Jeff; DAVIS, John (Eds.). A companion to the history of economic thought. Oxford and New York: Blackwell, 2003. p. 622-633.

CARDOSO, José Luís. A história nacional e o processo de difusão internacional das ideias económicas. In: AAVV, Miscellània Ernest Lluch i Martín. Vilassar de Mar: Fundació Ernest Lluch, 2006. v. I, p. 97-106.

COATS, A. W. Bob (Ed.). The post-1945 internationalisation of economics. Durham and London: Duke University Press, 1997.

(Annual supplement to HOPE, v. 28).

COATS, A. W. Bob (Ed.). The development of economics in Western Europe since 1945. London and New York: Routledge, 2000.

COLANDER, David C.; COATS, A. W. Bob. The spread of economic ideas. Cambridge and New York: Cambridge University Press, 1989.

DASGUPTA, Ajit. A bistory of Indian economic thought. London and New York: Routledge, 1993.
DELMAS, Bernard; DEMALS, Thierry; STEINER, Philippe. $L$ a diffusion internationale de la physiocratie (XVIIIe-XIXe).

Grenoble: Presses

Universitaires, 1995.

DOCKÈS, Pierre et al. Les traditions economiques francaises. Paris: Editions CNRS, 2000.

DORFMAN, Joseph. The role of the German Historical School in American economic thought. American Economic Review, v. 45, n. 2 , p. $17-28,1955$

FACCARELLO, Gilbert (Ed.). Studies in the history of French political economy. From Bodin to Walras. London and New York: Routledge, 1998.

GOODWIN, Craufurd D. W. Canadian economic thought. The political economy of a developing nation, 1814-1914. Durham, N. C.: Duke University Press, 1961.

GOODWIN, Craufurd D. W. Economic inquiry in Australia. Durham, N.C.: Duke University Press, 1966.

GOODWIN, Craufurd D. W. Economic theory and society: a plea for process analysis. American Economic Review, v. 62, n. 2 , p. $409-415,1972$
GOODWIN, Craufurd D. W. Marginalism moves to the New World. In: BLACK, R. D. C.; COATS, A. W.; GOODWIN, C. D. W. (Eds.). The marginal revolution in economics. interpretation and evaluation. Durham, N. C.: Duke University Press, 1973. p. 285-304. GROENEWEGEN, Peter; MCFARLANE, Bruce. A bistory of Australian economic thought. London and New York: Routledge, 1990.

HALL, Peter A. (Ed.). The political power of economic ideas. Princeton: Princeton University Press, 1989.

HASEK, Carl William. The introduction of Adam Smith's doctrines into Germany. New York: Columbia University, 1925.

HUTCHISON, T. W. Insularity and cosmopolitanism in economic ideas. American Economic Review, v. 45, n. 2, p. 1-16, 1955.

LAI, Cheng-Chung (Ed.). Adam Smith across nations: translations and receptions of the wealth of nations. Oxford: Oxford University Press, 2000.

LISBOA, José da Silva. Princípios de economia política para servir de introdução à tentativa económica do autor dos princípios de Direito Mercantil. Lisboa: Impressão Régia, 1804. 
LLOMBART, Vicent. Market for ideas and reception of physiocracy in Spain: some analytical and historical suggestions. The European Journal of the History of Economic Thought, v. 2, n. 1, p. 29-51, 1995.

LLUCH, Ernest. Sobre la historia nacional del pensamiento economico. Introduction to A. Florez Estrada. In: Curso de Economia Política (1828). Madrid: Instituto de Estudios Fiscales, 1980. (Reprint).

LLUCH, Ernest. Las historias nacionales del pensamiento económico y España. In: QUINTANA, Enrique Fuentes (Ed.). Economia y Economistas Españoles. Barcelona: Galaxia Gutemberg, 1999. v. 1, p. 435-476.

LOVE, Joseph. Structuralism and dependency in peripheral Europe: Latin American ideas in Spain and Portugal. Latin American Research Review, v. 39, n. 2 , p. 114-140, 2004.

MÄKI, Uskali. Economic thought on the outskirts: toward a historiographical framework for studying intellectual peripheries. Research in the History of Economic Thought and Methodology, v. 14, p. 307-23, 1996.

MIZUTA, Hiroshi; SUGIYAMA, Chuhei (Eds.). Adam Smith: international perspectives. London: Macmillan, 1993.

MORRIS-SUZUKI, Tessa. A bistory of Japanese economic thought. London and New York: Routledge, 1989.
NEILL, Robin. A bistory of Canadian economic thought. London and New York: Routledge, 1991.

PALYI, Melchior. The introduction of Adam Smith on the Continent. In: CLARK, J. M. et al. (Eds.). Adam Smith 1776-1926: Lectures to Commemorate the Sesquicentennial of the Publication of The Wealth of Nations. Chicago: University of Chicago Press, 1928.

PREBISCH, Raul. El desarollo de América Latina y algunos de sus principales problemas. El Trimestre Económico, v. 16, n. 63, 1949.

PSALIDOPOULOS, Michalis.

Keynesianism across nations: the case of Greece. The European Journal of the History of Economic Thought, v. 3, n. 3, 1996.

QUINTANA, Enrique Fuentes (Ed.). Economia y Economistas Españoles. Barcelona: Galaxia Gutemberg, 8 vols, 1999-2004.

SANDELIN, Bo. The history of Swedish economic thought. London and New York: Routledge, 1991.

SPENGLER, Joseph. Notes on the international transmission of economic ideas. History of Political Economy, v. 2, n. 1, p. 133-51, 1970.

STIGLER, George J. Nobel lecture: the process and progress of economics. Journal of Political Economy, v. 91, n. 4 p. 529-45, 1983.
SUGIYAMA, Chuhei; MIZUTA, Hiroshi (Eds.). Enlightenment and beyond. Political Economy Comes to Japan. Tokyo: University of Tokyo Press, 1988.

TRESCOTT, Paul B. Jingji Xue. The history of the introduction of Western economic ideas into China, 1850-1950. Hong Kong: The Chinese University Press, 2007.

TRIBE, Keith; MIZUTA, Hiroshi (Eds.). A critical bibliography of Adam Smith. London: Pickering \& Chatto, 2002.

VAN DAAL, J.; HEERTJE, A.

(Eds.). Economic thought in the

Netherlands: 1650-1950. Aldershot: Avebury, 1992.

VELARDE FUERTES, Juan. El movimiento estructuralista español. In: MOLERO, José (Ed.). El analisis estructural en economia: ensayos de America Latina y España, Mexico: Fondo de Cultura Econômica, 1981.

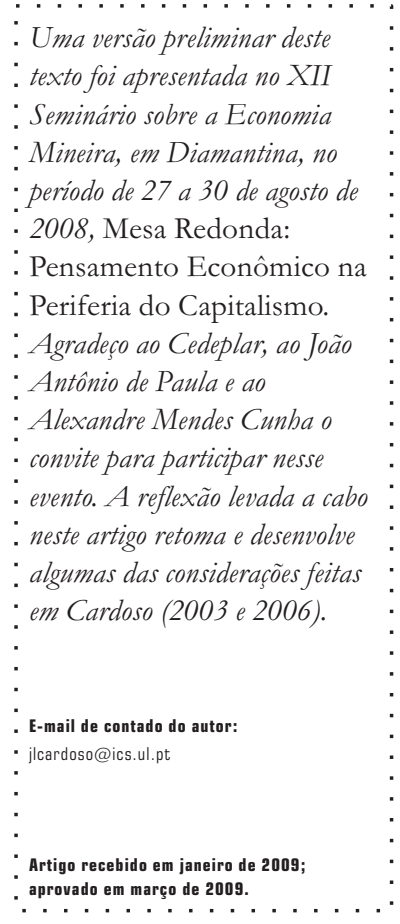

